\title{
A Retrospective Descriptive Study of Anaesthesia in Mobile Surgical Camps in Nepal
}

\author{
Bishwo Ram Amatya, Bhuban Raj Kunwar, Sunita Panta, Santosh Khadka, Mallika Rayamajhi \\ and Puja Thapa
}

Department of Anaesthesiology, Nepalese Army Institute of Health Sciences, Shree Birendra Hospital, Chhauni, Kathmandu, Nepal

\begin{abstract}
Introduction: Mobile medical and surgical camps are one of the means of providing medical and surgical facilities to people living in rural areas of developing country like Nepal.

Methods: An observational cross-sectional descriptive retrospective study was done collecting data from surgical camps done by Nepali Army in six years from February 2013 to February 2019 AD. Total number of surgical cases requiring anaesthesia along with type of anaesthesia, American Society of Anaesthesiologist physical status classification and anaesthesia related complications were collected.

Results: In a six year period, total 12 mobile surgical camps were conducted by Nepali Army. Out of which, two were done in collaboration with Ministry of Health, Government of Nepal. Total 703 surgical cases were conducted. Out of which, 583 were general surgical cases and 120 were gynaecological cases. 262 cases were done in local anaesthesia, 242 cases were done in spinal anaesthesia, 108 cases were done in total intravenous anaesthesia and 91 cases were done in general anaesthesia. Hypotension, nausea, vomiting, shivering, failed spinal and difficult airway were the complications noticed during intra-operative and postoperative period.

Conclusions: Surgical outreach camps are beneficial in providing surgical care to unaffordable people living in rural and remote areas where health care facilities are limited and inaccessible. Safety of patient is the key concern in such camps. Proper organised plan is required selecting target group of populations with target surgeries per day for successful conduction of safe surgeries in such camps.
\end{abstract}

Key words: anaesthesia; camps; mobile; surgical

Correspondence: Bishwo Ram Amatya, Department of Anaesthesia, Nepalese Army Institute of Health Sciences, Shree Birendra Hospital, Chhauni, Kathmandu, Nepal. E-mail:bishwo.amatya@naihs.edu.np.

DOI: http://dx.doi.org/10.3126/mjsbh.v19i1.24894

Submitted on: $2019-07-17$

Accepted on: 2019-12-09 


\section{INTRODUCTION}

According to Lancet commission on general surgery report 2015, surgery and anaesthesia care in low to medium income countries has been largely neglected. $28-32 \%$ of the global burden of disease can be attributed to surgically treatable conditions. Five billion people lack access to safe, affordable surgical and anaesthesia care when needed. 143 million additional surgical procedures are needed each year to save lives and prevent disability. 33 million individuals face catastrophic health expenditure due to payment for surgery and anaesthesia each year. Investment in surgical and anaesthesia services is affordable, saves lives, and promotes economic growth. ${ }^{1}$

In a low-income country like Nepal with a population of 26.5 million $^{2}$ and low Human Development Index 3 , only $43 \%$ of the people have access to all weather roads ${ }^{4}$ which limits accessibility to health care facilities for a larger proportion of Nepali population. Most of the people from rural parts of Nepal do not undergo surgery due to affordability, accessibility, or fear/no trust. ${ }^{5}$ Mobile Health Unit (MHU) is health strategy used to provide health services to population groups which have no access to a health-care system due to financial and geographical barrier. Mobile surgical camps are one of such MHU that provides short term surgical services lasting from seven to 10 days. ${ }^{6}$ Surgical camps are organised time to time by government and private hospitals/institutions in collaboration with Ministry of Health $(\mathrm{MOH})$ and national/international agencies. ${ }^{7}$ Safety of patients in such camps is major concern for which proper organised plan is required..$^{8-11}$

The objectives of this study were to evaluate anaesthetic practice in surgical outreach camps in Nepal and to describe surgical camp module as an approach to improve access to surgical services to target communities.

\section{METHODS}

A retrospective designed descriptive cross sectional study was done targeting retired army along with their dependents (two children, spouse and parents) and unaffordable civilians willing to give consents for surgery. The study area included were four schools (Dhangadi, Dharan, Surkhet, Butwal), six mobile hospitals (Nepalgunj, Pokhara, Dhangadi, Sindhuli, Itahari, Dhanusa), one district hospital in Gaur and one zonal hospital in Rajbiraj (Sagarmatha Zonal Hospital) involving medical team from army tertiary care hospital alone or in collaboration with Ministry of Health. 12 mobile surgical camps during last six years from February 2013 to Feb 2019 were included. Inclusion criteria were both male and female populations of all ages, all elective general surgeries and gynaecological surgeries, American Society of Anaesthesiologist physical status (ASA) class I \& ASA class II. All study population with ASA III and ASA IV, those unfit for surgery like fever, anaemia, diarrhoea, upper respiratory tract infection and all emergency surgeries were excluded from the study. Similarly all anticipated difficult airway cases were excluded for elective surgeries.

After obtaining approval from Institution Review Board (IRB) to conduct study, data were collected from Anaesthesiologists involved in the camps and confirmed from post camp records that were made available from camp commanders. Data collected were firstly demographic profile like age, sex of patients, year and place where camp were conducted; secondly surgical profile like number of surgeries done, type of surgery, clinical diagnosis and finally anaesthetic profile like ASA physical status classification, types of anaesthesia and complications of anaesthesia. Graph pad prism version 8 was used for statistical analysis and the tools used were frequency distribution in terms of tables and graphs.

Before conducting all those camps mentioned in our study, preliminary survey and screening of the camps area was done at least one month before. During this period, selection of the area, Outpatient Department (OPD), Operation Theatre (OT), Preoperative room, post-operative room, laboratory, radiology, Central Sterile Service Department (CSSD) etc were done. Preparation of required drugs list, equipments list, and resources required along with other logistics required were listed. 
Target populations and target surgeries per day were determined. Coordination with local authorities was also done. Public awareness of camp was done using local FM radio and local television, mike announcement, pamphlets or banners. Similarly patient screening was done two weeks before satellite OPD by medical officer of Army Hospital, district hospital and zonal hospital. Just one week before conduction of camp, final screening of area, patient and coordination was done. Final preparation before surgical camps was done by preparing OT using cleaning, disinfection and sterilisation method. Similarly, anaesthesia machine, OT lights/table, crash cart, monitor, oxygen cylinders, backup generator, suction machine and cautery machine were assembled and checked. Pre-anaesthesia checkups of patients for next day were done one day before surgery. An anaesthesiologist and an anaesthesia assistant were present all the time during operation. Difficult airway protocol was implemented as per American Society of Anaesthesiologists guidelines. Mobile hospitals were assembled in open ground where roads were accessible. Postoperative pain was managed with multimodal analgesia with local infiltration at surgical site, Non-steroidal antiinflammatory drugs like intravenous paracetamol, Ketorolac etc and opioids like intravenous Tramadol and intramuscular Pethidine and Promethazine as when required.

\section{RESULTS}

Out of 12 camps conducted in six years, 10 were conducted by Army Hospital involving four schools and six mobile hospitals. Rest two were conducted by Army Hospital in collaboration with Ministry of Health involving one district hospital in Gaur and one zonal hospital in Rajbiraj. Duration of each camp was not more than 12 days. Out of 703 total numbers of surgical cases done, 461 cases were done by Army Hospital in collaboration with Ministry of Health $(\mathrm{MOH})$ and remaining 242 cases were done by Army Hospital alone as shown in Figure 1. As shown in Table 1, out of 703 cases, 583 were general surgical cases whereas remaining 120 were gynaecological cases.
Army camp alone

Army camp in collaboration with $\mathrm{MOH}$

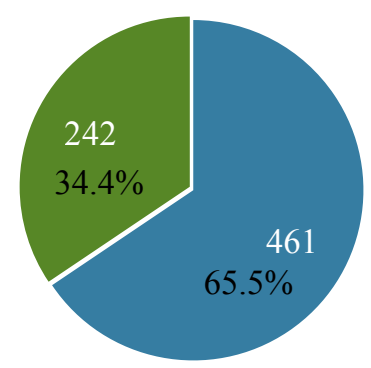

Figure 1. Distribution of surgical cases by army hospital alone or in collaboration with $\mathrm{MOH}$

Similarly as shown in Figure 2 and Figure 3 out of 703 cases, 430 cases were males where as remaining 273 cases were females. Similarly, 18 cases belonged to $1-5$ years, 39 cases to $6-17$ years, 551 cases to $18-65$ years and 95 cases to $>65$ years age group.

According to ASA, physical status classification and distribution of surgical cases were done as shown in Figure 4. 569 cases were ASA I and

Table 1. Distribution of cases in terms of year, place, gender, age and types of surgeries

\begin{tabular}{|c|c|c|c|c|}
\hline Year & Place & $\begin{array}{l}\text { General } \\
\text { Surgical } \\
\text { Cases }\end{array}$ & $\begin{array}{l}\text { Gynecolo } \\
\text { gical } \\
\text { Cases }\end{array}$ & Total \\
\hline 2013 & Dhangadi & 69 & 3 & 72 \\
\hline 2013 & Dharan & 15 & 1 & 16 \\
\hline 2014 & Surkhet & 16 & 1 & 17 \\
\hline 2014 & Butwal & 14 & 1 & 15 \\
\hline 2014 & Nepalgunj & 11 & 1 & 12 \\
\hline 2014 & Pokhara & 10 & 2 & 12 \\
\hline 2017 & Dhangadi & 10 & 1 & 11 \\
\hline 2017 & Sindhuli & 15 & 2 & 17 \\
\hline 2018 & Itahari & 32 & 10 & 42 \\
\hline 2018 & Rautahat & 114 & 50 & 164 \\
\hline 2018 & Dhanusa & 22 & 6 & 28 \\
\hline 2019 & Rajbiraj & 255 & 42 & 297 \\
\hline $\begin{array}{l}\text { Grand } \\
\text { Total }\end{array}$ & & $\begin{array}{l}583 \\
(82.93 \%)\end{array}$ & $\begin{array}{l}120 \\
(17.06 \%)\end{array}$ & 703 \\
\hline
\end{tabular}




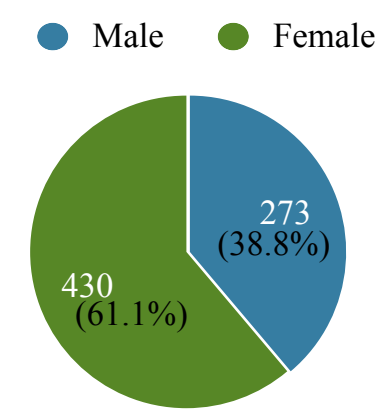

Figure 2. Sex wise distribution of cases in mobile surgical camps

remaining 134 cases were ASA II. Similarly, as shown in Figure 5, out of 703 cases, 262 cases were done under local anaesthesia, 242 cases were done under spinal anaesthesia, 108 cases were done under total intravenous anaesthesia and remaining 91 cases were done under general anaesthesia.

Out of 583 general surgical cases done, common surgical procedures were minor surgery (255 cases), mesh repair (148 cases) and open cholecystectomy (60 cases) as shown in Table 2. Similarly, as shown in Table 3, out of 120 gynaecological cases done, common surgical procedures were Vaginal Hysterectomy with Pelvic Floor Repair / VH PFR (43), Total abdominal hysterectomy/TAH (20) and cervical /endometrial biopsy (20). Among the common anaesthetic complications noted during camps as shown in Table 4 were nausea and vomiting (56), Hypotension (48) and Shivering (34). There was one difficult airway case managed with airway manipulation, use of stylet and number 4 laryngoscope blade.

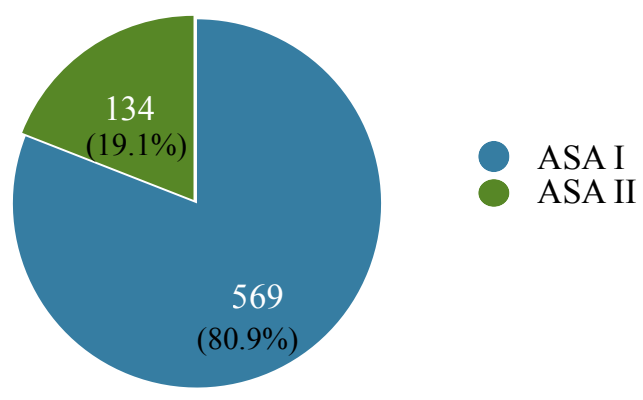

Figure 4. American Society of Anaesthesiologists (ASA) wise case distribution

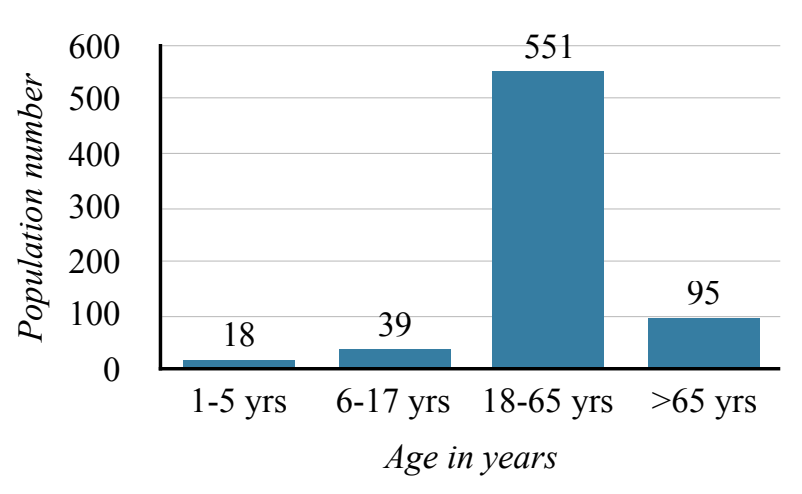

Figure 3. Age wise distribution of cases in mobile surgical camps

Other surgical cases in Table 2 include surgeries like breast lump excision, dermoid cyst excision, rectal prolapse surgery, nephrectomy, pyelolithotomy, modified radical mastectomy, cystolithotomy, choledocholithotomy, orchidopexy and orchidectomy. Similarly minor surgery included surgery for lipoma, fibroma, ganglionoma, sebaceous cyst, corn excision, ingrowing toe nail excision, hydrocele etc. Gynaecological procedures included cervical amputation, ovarian cyst surgery and colporraphy (Table 3).

\section{DISCUSSION}

Among the 12 camps conducted, $65.57 \%$ surgeries were conducted in those camps done in collaboration with Ministry of Health as compared to those conducted by army alone (34.43\%) suggesting of better coordination, communication and logistic support along with involvement of more civilian population apart from regular, ex army men and their dependents. Majority of target population were males $(61.16 \%)$ mainly because surgical problems like inguinal hernia ${ }^{12}$, hydrocele,

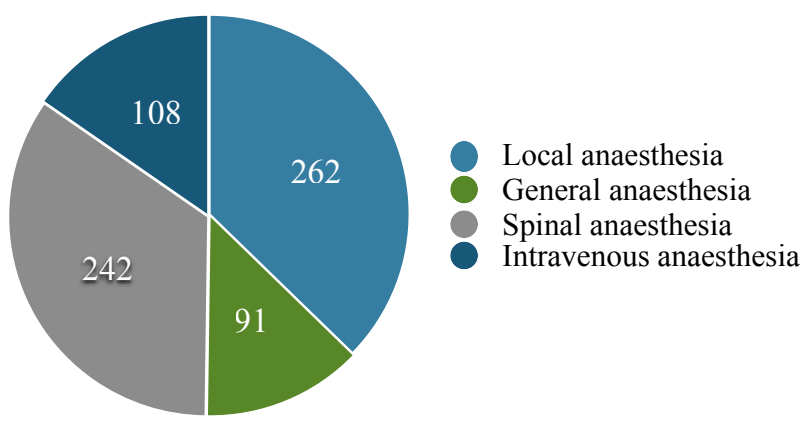

Figure 5. Distribution of surgical cases done in terms of anaesthetic technique 
Table 2. General surgical procedures done in mobile surgical camps

\begin{tabular}{|c|c|c|c|c|c|c|c|c|c|c|c|}
\hline Year & Place & $\begin{array}{l}\text { Minor } \\
\text { surgery }\end{array}$ & $\begin{array}{l}\text { Mesh } \\
\text { Repair }\end{array}$ & $\begin{array}{l}\text { Hemorroid } \\
\text { ectomy }\end{array}$ & $\begin{array}{l}\text { Fistula/ } \\
\text { Fissure } \\
\text { surgery }\end{array}$ & $\begin{array}{l}\text { Open } \\
\text { cholecys } \\
\text { tectomy }\end{array}$ & $\begin{array}{l}\text { Incision } \\
\text { and } \\
\text { Drainage }\end{array}$ & $\begin{array}{l}\text { Circum } \\
\text { cision }\end{array}$ & Hydrocele & $\begin{array}{l}\text { Hernioto } \\
\text { my }\end{array}$ & others \\
\hline 2013 & Dhangadi & 50 & 6 & 2 & 1 & 0 & 3 & 4 & 1 & 0 & 2 \\
\hline 2013 & Dharan & 9 & 3 & 3 & 0 & 0 & 0 & 0 & 0 & 0 & 0 \\
\hline 2014 & Surkhet & 11 & 3 & 1 & 0 & 0 & 0 & 0 & 0 & 0 & 1 \\
\hline 2014 & Butwal & 8 & 3 & 0 & 0 & 0 & 1 & 0 & 0 & 0 & 2 \\
\hline 2014 & Nepalgunj & 5 & 3 & 1 & 0 & 0 & 1 & 0 & 0 & 0 & 1 \\
\hline 2014 & Pokhara & 6 & 2 & 1 & 0 & 0 & 0 & 0 & 0 & 0 & 1 \\
\hline 2017 & Dhangadi & 5 & 3 & 0 & 0 & 0 & 1 & 0 & 0 & 0 & 1 \\
\hline 2017 & Sindhuli & 8 & 4 & 0 & 0 & 0 & 1 & 1 & 0 & 0 & 1 \\
\hline 2018 & Itahari & 12 & 10 & 2 & 2 & 0 & 1 & 0 & 1 & 1 & 3 \\
\hline 2018 & Rautahat & 62 & 16 & 3 & 2 & 6 & 3 & 4 & 5 & 4 & 9 \\
\hline 2018 & Dhanusa & 9 & 10 & 2 & 0 & 0 & 0 & 0 & 0 & 1 & 0 \\
\hline 2019 & Rajbiraj & 70 & 85 & 1 & 4 & 54 & 1 & 7 & 10 & 0 & 23 \\
\hline Total & & 255 & 148 & 16 & 9 & 60 & 12 & 16 & 17 & 6 & 44 \\
\hline
\end{tabular}

anorectal fistula/fissure and haemorrhoids are common in males. ${ }^{13}$ The common age groups that had anaesthesia for surgical procedures were 18 to 65 years of age $(78.37 \%)$ mainly because general surgical cases like hernia, hydrocele, cholecystectomy and gynaecological cases like abdominal hysterectomy, vaginal hysterectomy are found in this age groups. ${ }^{12-14}$

Table 3. Gynaecological procedures done in mobile surgical camp

\begin{tabular}{|c|c|c|c|c|c|c|c|c|}
\hline Year & Place & TAH & VH PFR & $D$ and $C$ & $\begin{array}{l}\text { Vaginal cyst } \\
\text { excision }\end{array}$ & Polypectomy & $\begin{array}{l}\text { Cervical / } \\
\text { Endometrial Biopsy }\end{array}$ & Others \\
\hline 2013 & Dhangadi & 0 & 0 & 0 & 0 & 0 & 3 & 0 \\
\hline 2013 & Dharan & 0 & 0 & 0 & 0 & 0 & 1 & 0 \\
\hline 2014 & Surkhet & 0 & 0 & 0 & 0 & 0 & 1 & 0 \\
\hline 2014 & Butwal & 0 & 0 & 0 & 0 & 0 & 1 & 0 \\
\hline 2014 & Nepalgunj & 0 & 0 & 0 & 0 & 0 & 1 & 0 \\
\hline 2014 & Pokhara & 0 & 0 & 0 & 0 & 0 & 2 & 0 \\
\hline 2017 & Dhangadi & 0 & 0 & 0 & 0 & 0 & 1 & 0 \\
\hline 2017 & Sindhuli & 0 & 0 & 0 & 0 & 0 & 2 & 0 \\
\hline 2018 & Itahari & 0 & 0 & 1 & 2 & 2 & 2 & 0 \\
\hline 2018 & Rautahat & 0 & 38 & 3 & 3 & 2 & 2 & 4 \\
\hline 2018 & Dhanusa & 0 & 0 & 0 & 1 & 2 & 1 & 0 \\
\hline 2019 & Rajbiraj & 20 & 5 & 4 & 2 & 6 & 3 & 5 \\
\hline Total & & 20 & 43 & 8 & 8 & 12 & 20 & 9 \\
\hline
\end{tabular}


Table 4. Anaesthesia related complications during surgical camps

\begin{tabular}{|c|c|c|c|c|c|c|c|c|c|}
\hline Year & Place & Hypotension & $\begin{array}{l}\text { Nausea/ } \\
\text { Vomiting }\end{array}$ & Shivering & Arrythmia & $\begin{array}{l}\text { Failed } \\
\text { spinal }\end{array}$ & $\begin{array}{l}\text { Partial } \\
\text { spinal }\end{array}$ & $\begin{array}{l}\text { Difficult } \\
\text { airway }\end{array}$ & $\begin{array}{l}\text { Urinary } \\
\text { retention }\end{array}$ \\
\hline 2013 & Dhangadi & 2 & 3 & 1 & 2 & 0 & 0 & 0 & 0 \\
\hline 2013 & Dharan & 0 & 0 & 0 & 0 & 0 & 0 & 0 & 0 \\
\hline 2014 & Surkhet & 1 & 1 & 1 & 0 & 0 & 0 & 0 & 0 \\
\hline 2014 & Butwal & 0 & 0 & 0 & 0 & 0 & 0 & 0 & 0 \\
\hline 2014 & Nepalgunj & 0 & 0 & 0 & 0 & 0 & 0 & 0 & 0 \\
\hline 2014 & Pokhara & 0 & 0 & 0 & 0 & 0 & 0 & 0 & 0 \\
\hline 2017 & Dhangadi & 0 & 0 & 0 & 0 & 0 & 0 & 0 & 0 \\
\hline 2017 & Sindhuli & 0 & 0 & 0 & 0 & 0 & 0 & 0 & 0 \\
\hline 2018 & Itahari & 2 & 2 & 2 & 1 & 0 & 0 & 0 & 0 \\
\hline 2018 & Rautahat & 14 & 15 & 12 & 4 & 0 & 1 & 0 & 2 \\
\hline 2018 & Dhanusa & 0 & 1 & 0 & 1 & 0 & 0 & 0 & 0 \\
\hline 2019 & Rajbiraj & 29 & 34 & 18 & 8 & 1 & 4 & 1 & 3 \\
\hline Total & & 48 & 56 & 34 & 16 & 1 & 5 & 1 & 5 \\
\hline
\end{tabular}

Similarly general surgical procedures $(82.93 \%)$ were more common than gynaecological procedures (17.06\%). This might be due to lack of awareness and lack of trust or fear among female populations. Among the 583 general surgical procedures, common surgeries were minor surgeries (255) along with mesh repair for inguinal hernia (148) and open cholecystectomy (60).

Most of the surgical cases done were ASA I $(80.93 \%)$ as compared to ASA II (19.07\%). This is because ASA I cases have fewer intra-operative and postoperative complications with better outcome following surgery. ${ }^{15-17}$ Local anaesthesia and spinal anaesthesia with or without intravenous sedation were preferred over general anaesthesia in our study. Choice of anaesthetic technique was based on surgical procedure. Loco-regional anaesthesia should be used wherever appropriate considering safety of patient. ${ }^{8,10}$ Most of the anaesthetic complications noted in our study were nausea, vomiting, hypotension and shivering which were mainly due to spinal anaesthesia. ${ }^{18}$ The settings, preparation and execution of camps mentioned in our study along with anaesthetic technique used, and postoperative preparation were similar to that mentioned by Bhattarai $\mathrm{B}^{8}$, Gnanaraj $\mathrm{J}^{9}$, Galukunde $\mathrm{M}^{10}$ and Shah $\mathrm{JN}^{11}$. The only difference in our study is use of mobile hospitals where mobile vehicles were assembled in open ground. They were used to run outpatient services, minor surgery, and diagnostic facilities.

\section{CONCLUSIONS}

Surgical outreach camps are beneficial in providing surgical care. Mobile hospitals can be one of the camp modules in areas where road access is available with collaboration with district or zonal hospitals. Providing safe anaesthesia in a mobile surgical camp remains a challenge. Proper organisation, plan and preparation are required before conducting such camps. Spinal anaesthesia is the preferred anaesthetic technique for providing safe anaesthesia for intermediate to major surgeries.

\section{RECOMMENDATIONS}

A set guidelines and standard operative procedures should be made available for mobile medical and surgical camps. While making such guidelines following $\mathrm{ABCDEF}$ of camp based health care delivery can be followed: 

A: Awareness \& Availability of 6S (Survey,
Space, Sanitation, Services, Sterility, Staff)
B: Basic training of staffs
C: Checklist
D: Delivery of standard health care services
E: Emergency \& Exit services
F: Feedback, Follow up \& Future strategy

\section{LIMITATIONS}

One of the limitation of our study was to include only general surgical and gynaecological procedures as target surgeries. This was because of logistic issues of equipments required for other types of surgeries. Similarly, the study could have included other camps done in areas where road access is not present.

\section{ACKNOWLEDGEMENTS}

I would like to acknowledge all my senior faculties (Prof Dr Nagendra Bahadur K.C. and Assoc Prof Dr Udaya Bajracharya,) and juniors of Department of Anaesthesiology (Lecturer Dr Thaneswor Rijal, Lecturer Dr Aasish Shah) for their valuable inputs. I would also like to acknowledge the Commandant of Shree Birendra Hospital, Chaauni for allowing me to conduct the research. Similarly, I would also like to acknowledge all camp commanders involved in military mobile surgical camps for providing detail camp records.

To cite this article: Amatya BR, Kunwar BR, Panta S, Khadka S, Rayamajhi M, Thapa P. A retrospective descriptive study of anaesthesia in mobile surgical camps in Nepal. MJSBH. 2019;19(1):2-9.

Conflict of Interest: None declared

\section{REFERENCES}

1. Meara J, Leather A, Hagander L, Alkire BC, Alonso N, Ameh EA, et al. Global Surgery 2030: Evidence and Solutions for Achieving Health, Welfare, and Economic Development. Lancet. 2015;386:569-624. DOI: $10.1016 / \mathrm{s} 0140-6736$.

2. National Population and Housing Census 2011. Central Bureau of Statistics, Government of Nepal. Volume 01. 2012.

Available from: http://mofald.gov.np/

3. Malik K. United Nations Development Programme, Human Development Report 2014; 2014. Available from: http://hdr.undp.org

4. Gupta S, Shrestha S, Ranjit A, Nagarajan N, Groen RS, Kushner AL, et al. Conditions, preventable deaths, procedures and validation of a countrywide survey of surgical care in Nepal. Br J Surg. 2015;102(6):700-7. DOI: $10.1002 /$ bjs. 9807

5. Van Loenhout JA, Delbiso TD, Gupta S, Amatya K, Kushner AL, Cuesta JG, et al. Barriers to surgical care in Nepal. BMC Health Serv Res. 2017;17(1):72.

DOI: $10.1186 / \mathrm{s} 12913-017-2024-7$

6. Guillouzic H. Mobile Health Unit: a methodical approach 2006 May. International Committee of Red Cross. Available from: www.icrc.org

7. Pandey A, Paudel P, Paudel L. Scenario of Health Camps in Nepal. JNHRC. 2011;9(18):86-8. DOI: https://doi.org/10.33314/jnhrc.v0i0.263

8. Bhattarai B. Anaesthesia in outreach surgical camps: more of arts than science. JSAN. 2016;3:2-7. DOI: $10.3126 /$ jsan.v3i1.14654

9. Gnanaraj J, Jamir S. Surgical services initiative: Taking modern surgery to poor. CHRISMED J Health Res. 2014;1(3):194-97.

DOI: $10.4103 / 2348-3334.138900$

10. Galukunde M, Kituuka O, Elobu E. Improving surgical access in rural Africa through surgical camp model. Surgery research and practice 2016. 
DOI: $10.1155 / 2016 / 9021945$

11. Shah JN. Taking Specialist Surgical Services to the Rural District Hospitals at One Forth Cost: A Sustainable 'Return on Investment' Public Health Initiative of Patan Hospital, Patan Academy of Health Sciences, Nepal. KUMJ. 2015;50(2):186-92. DOI: 10.3126/kumj.v13i2.16797

12. Stewart B, Mcintyre T. An estimate of hernia prevalence in Nepal from a countrywide community survey. IJS. 2015;13:111-4.

DOI: $10.1016 /$ j.ijsu.2014.12.003

13. Gupta S, Ranjit A, Shrestha R, Wong EG, Robinson WC, Shrestha S, et al. Surgical needs of Nepal: pilot study of population based survey in Pokhara, Nepal. World J Surg. 2014;38(12):3041-6.

DOI: $10.1007 / \mathrm{s} 00268-014-2753-2$

14. Fleming M, King C, Rajeev S, Baruwal A, Schwarz D, Schwarz R, et al. Surgical referral coordination from a firstlevel hospital: a prospective case study from rural Nepal. BMC Health Serv Res. 2017;17(1):676-9.

DOI: $10.1186 / \mathrm{s} 12913-017-2624-2$

15. Daabisis M. American Society of Anaesthesiologists physical status classification. Indian J Anaesth. 2011;55(2): 111-5.

DOI: 10.4103/0019-5049.79879. PMID: 21712864.

16. Mayhew D, Mendonca V, Murthy BVS. A review of ASA physical status-historical perspectives and modern developments. Anaesthesia. 2019;74(3):373-9.

DOI: 10.1111/anae.14569

17. Hackett NJ, De Oliveira GS, Jain UK, Kin JY. ASA class is a reliable independent predictor of medical complications and mortality following surgery. Int J Surg. 2015;18:184-90.

DOI: 10.1016/j.ijsu.2015.04.079

18. Kılı̨̧ Y. Spinal Anaesthesia and Neurological Complications: A Brief Report. JAMMR.2016;15:1-7.

DOI: $10.9734 / \mathrm{BJMMR} / 2016 / 27158$ 